Revista Brasileira de Agricultura Irrigada v.14, nº.1, p. 3889 - 3896, 2020

ISSN 1982-7679 (On-line)

Fortaleza, CE, INOVAGRI - http://www.inovagri.org.br

DOI: $10.7127 /$ rbai.v14n1001155

Protocolo 1155.20 - 26/04/2019 Aprovado em 08/05/2020

\title{
PRODUÇÃO DE ALFACE AMERICANA SOB DIFERENTES LÂMINAS E FREQUÊNCIAS DE IRRIGAÇÃO
}

\author{
Cicero Lima de Almeida ${ }^{1}$, James do Nascimento Costa ${ }^{2}$, Pedro Oliveira Filho ${ }^{2}$, Joilson Silva Lima ${ }^{3}$, \\ Manoel Valnir Júnior ${ }^{4}$
}

\section{RESUMO}

A produção de alface do tipo americana tem crescido em todo o Brasil nos últimos anos. O seu cultivo irrigado e em ambiente protegido pode garantir que o produto seja oferecido durante todo o ano. Desse modo, o trabalho teve como objetivo avaliar diferentes lâminas e frequências de irrigação sobre a produção da alface americana. $\mathrm{O}$ experimento foi realizado em telado agrícola, com as plantas cultivadas em vasos, em delineamento inteiramente casualizado com quatro repetições, em esquema fatorial de $3 \times 5$, referente a 3 frequências de irrigação (F1 - duas vezes ao dia; F2 - uma vez ao dia; F3 - dias alternados) e cinco lâminas de irrigação (L1-25\%; L2-50\%, L3-75\%; L4-100\% e L5-125\% da Evaporação do minitanque, Evm). As variáveis analisadas foram: massa fresca comercial (MFC); altura da planta (AP) e uso eficiente da água (UEA). Concluiu-se que tanto o aumento da lâmina e como da frequência de irrigação promoveram aumento da produtividade da cultura. A resposta do UEA foi inversamente proporcional ao aumento da lâmina de irrigação. Contudo, as condições climáticas observadas, principalmente temperatura, não proporcionaram a formação da cabeça da alface americana, e consequentemente seu estiolamento.

Palavras-Chave: Lactuca sativa, uso eficiente da água, cultivo protegido.

\section{AMERICAN LETTUCE PRODUCTION UNDER DIFFERENT IRRIGATION FREQUENCY AND DEPTHS}

\footnotetext{
ABSTRACT

The production of lettuce of the American type has grown in Brazil in recent years and its irrigated and protected cultivation can guarantee that the product is offered throughout the year. In this way,

${ }^{1}$ Dr. Engenharia Agrícola, Eixo de Recursos Naturais, IFCE - Campus Sobral, Av. Dr. Guarani, 317 - Derby Clube, Sobral - CE, 62042-030, e-mail: cicero.almeida@ifce.edu.br

${ }^{2}$ Tecnólogo em Irrigação e Drenagem, Eixo de Recursos Naturais, IFCE - Campus Sobral, e-mail: jamesnascimento07@gmail.com; pedrooliveira1998.pfo@gmail.com

${ }^{3}$ Dr. Fitotecnia, Eixo de Recursos Naturais, IFCE - Campus Sobral, e-mail: joilson.lima@ifce.edu.br

${ }^{4}$ Dr. Engenharia Agrícola, Eixo de Recursos Naturais, IFCE - Campus Sobral, e-mail: valnirjvm@yahoo.com.br
} 
the work aimed to evaluate different irrigation depths and frequency on American lettuce production. The experiment was conducted in a greenhouse, with plants cultivated in pots, in factorial of $3 \times 5$ ( 3 frequency x 5 depths), with four replicates. The treatments were irrigation frequency (F1-twice a day; F2-once a day; F3-alternate days) and depths (L1-25\%; -50\% L2, L3-75\%; L4-L5-100\% and $125 \%$ mini tank evaporation, Evm). The variables analysed were: commercial fresh mass (CFM); plant height (PA); and, efficient use of water (EUW). It was concluded that both the increase in the depths and the frequency of irrigation promoted an increase in crop productivity. The EUW response was inversely proportional to the increase in the irrigation depth. However, the climatic conditions observed, mainly temperature, did not provide the formation of the head of the American lettuce, and consequently its stretching.

Keywords: Lactuca sativa, efficient use of water, protected cultivation.

\section{INTRODUÇÃO}

A alface (Lactuca sativa L.), originária da região mediterrânea, é considerada a principal hortaliça folhosa no mundo (MARCHI et al., 2015). No mercado brasileiro, destaca-se entre as hortaliças de grande importância (COSTA et al., 2019; RODRIGUES et al., 2008) e as cultivares existentes são classificadas com base na formação de cabeça e do tipo de folhas, caracterizando cinco tipos morfológicos principais: Repolhuda Lisa, Repolhuda Crespa ou Americana, Solta Lisa, Solta Crespa e Tipo Romana (HENZ; SUINAGA, 2009).

$O$ volume de alface comercializado na CEAGESP em 2014 foi de 48,6 mil toneladas (AGRIANUAL, 2015), revelando que a alface do tipo americana possui $26,9 \%$ da preferência dos consumidores, em função das mudanças nos hábitos alimentares e do crescimento das redes de lanchonetes de "fast food" (SALA; COSTA, 2012), associadas às características foliares (imbricadas e crocantes) e de comercialização, suportando melhor o processamento e a pós-colheita, apresentando maior resistência no transporte e manuseio (BRZEZINSKI et al., 2017).

Para manter a regularidade de oferta da hortaliça durante todo o período do ano, o cultivo em ambiente protegido pode garantir que o produto seja oferecido mesmo quando as variações climáticas não favorecem o cultivo convencional (VALERIANO et. al., 2016).

Em regiões semiáridas, a produção é limitada principalmente pela água, tanto em quantidade como em qualidade. Essa limitação deve ser levada em conta, buscando-se utilizar com máxima eficiência este recurso, dispondo da irrigação para tal finalidade. Entretanto, o manejo inadequado do sistema de irrigação e da cultura pode inviabilizar o processo de produção (VALERIANO et al., 2016).

Entre os sistemas de irrigação disponíveis, o mais recomendado para casas de vegetação é o localizado, tipo gotejamento, por apresentar maior eficiência de aplicação e controle da lâmina de irrigação, beneficiando desta forma a cultura da alface, considerada como exigente em água (KOETZ et al., 2006) A planta apresenta maior sensibilidade ao estresse hídrico na fase de desenvolvimento vegetativo (SANTOS et al. 2015), sendo necessário, segundo Santos e Pereira (2004), a aplicação de água com maior frequência e menor intensidade de aplicação ao longo do ciclo da cultura.

Desse modo, o trabalho teve como objetivo avaliar diferentes lâminas e frequências de irrigação sobre a produção da alface americana, cultivar "Gloriosa", determinando qual a lâmina e frequência proporcionam maior eficiência no uso da água.

\section{MATERIAL E MÉTODOS}

O experimento foi conduzido em telado agrícola (com sombreamento de 50\%), pertencente ao Instituto Federal de Educação, Ciência e Tecnologia - IFCE/Campus Sobral, no período de novembro e dezembro de 2013. O clima da região segundo classificação de Köppen é Aw”, com precipitação média (1961 
- 2016) de 896,7 mm, concentradas entre janeiro e maio, com temperaturas máximas variando de $37,7^{\circ} \mathrm{C}$ em outubro e $29,4^{\circ} \mathrm{C}$ em maio e temperaturas mínimas variando de $24,7^{\circ} \mathrm{C}$ em dezembro e $18,5^{\circ} \mathrm{C}$ em julho, com umidade relativa do ar média de $70 \%$ e insolação anual média de 2648 h (INMET, 2018). As plantas de alface americana "Gloriosa" foram conduzidas vaso (1 planta vaso $^{-1}$ ), com espaçamento de $0,30 \mathrm{~m}$ entre linhas e $0,25 \mathrm{~m}$ entre plantas.

Os vasos, com capacidade de $7 \mathrm{dm}^{3}$, foram preenchidos com substrato composto por três partes de solo para uma de esterco bovino, tendo suas características físicoquímicas determinadas no Laboratório de Solos do IFCE/Campus Sobral, procedendo a adubação segundo recomendações de Aquino et al. (1993).

A semeadura de alface foi realizada em substrato composto por bagana de coco mais esterco bovino curtido (1:1), em bandejas de poliestireno expandido, com 128 células. A emergência de $94 \%$ das sementes das mudas ocorreu com entre o quinto e o sexto dia após a semeadura. $\mathrm{O}$ transplantio das mudas ocorreu no décimo dia após a emergência (DAE) das plantas, com os tratamentos iniciados aos 15 DAE.

O sistema de irrigação utilizado foi do tipo localizado, com um emissor por planta, vazão de $1,94 \mathrm{~L} \mathrm{~h}^{-1}$ e pressão de serviço de $98,0 \mathrm{kPa}$, e o manejo realizado por meio da evaporação de um minitanque tanque classe $\mathrm{A}$, instalado no centro do telado, sobre um estrado de madeira com altura de $15 \mathrm{~cm}$ acima do solo. O tempo de aplicação de água em cada frequência e lâmina foi determinado seguindo a equação 1 , definida por:

$T=\left(\frac{E v \times F_{L} \times A_{p}}{n \times q \times E f}\right) \times$ Freq.

Em que: T - tempo de irrigação (h); Ev evaporação do minitanque classe A (mm); $F_{L}$ fator lâmina de irrigação (decimal); Ap adotou-se na fase inicial a área vaso (15 a 29 DAE) e posteriormente a área da planta $\left(\mathrm{m}^{2}\right)$; $\mathrm{n}$ - número de emissores por planta (adimensional); q - vazão do emissor $\left(\mathrm{L} \mathrm{h}^{-1}\right)$; Ef - eficiência da aplicação de água (decimal); e Freq. - frequência de irrigação (dias).

O controle de plantas daninhas foi realizado manualmente, sempre quando se observou o crescimento das invasoras. Durante o ciclo foi aplicada a calda bordalesa de modo preventivo a cada quinze dias conforme recomendação Ponte e Ponte (2008).

$\mathrm{O}$ delineamento experimental utilizado foi o inteiramente casualizado com quatro repetições, em esquema fatorial de 3 x 5, referentes a 3 frequências de irrigação (F1 duas vezes ao dia; F2 - uma vez ao dia; F3 dias alternados) e cinco lâminas de irrigação (L1-25\%; L2-50\%, L3-75\%; L4-100\% e L5$125 \%$ da Evaporação do minitanque, Evm).

Aos 50 DAE, foram realizadas as análises das seguintes variáveis: produtividade comercial $\left(\mathrm{PC}, \mathrm{kg} \mathrm{ha}{ }^{-1}\right)$, representada pela parte comercial utilizada para o consumo, após a retirada das folhas externas; altura da planta (AP, cm), medida após a retirada de todas as folhas; e, uso eficiente da água (UEA, $\mathrm{kg} \mathrm{m}^{-3}$ ), calculado pela razão entre a MFC $\left(\mathrm{kg} \mathrm{ha}^{-1}\right)$ e o volume de água aplicado por ha $\left(\mathrm{m}^{3} \mathrm{ha}^{-1}\right)$.

Todas as variáveis analisadas apresentaram distribuição normal pelo teste de Shapiro-Wilk ( $>>0,05)$. Desse modo, os dados foram submetidos a análise de variância (ANOVA) pelo teste $\mathrm{F}(\mathrm{p}>0,05)$ e, quando observado efeito significativo quanto a lâmina e frequência de irrigação, realizou-se a análise de regressão. As análises foram realizadas no software SPSS 20.0.

\section{RESULTADOS E DISCUSSÃO}

A evaporação no minitanque classe A e da precipitação dentro do telado agrícola durante o período de estudo foram de $124,1 \mathrm{~mm}$ e 13,6 mm, respectivamente (Figura 1A). Enquanto a média da temperatura do ar e da umidade relativa do ar foram de $30,7^{\circ} \mathrm{C}$ e $54,3 \%$, respectivamente (Figura $1 \mathrm{~B}$ ). Todas as variáveis climáticas foram obtidas diariamente às dez horas. 

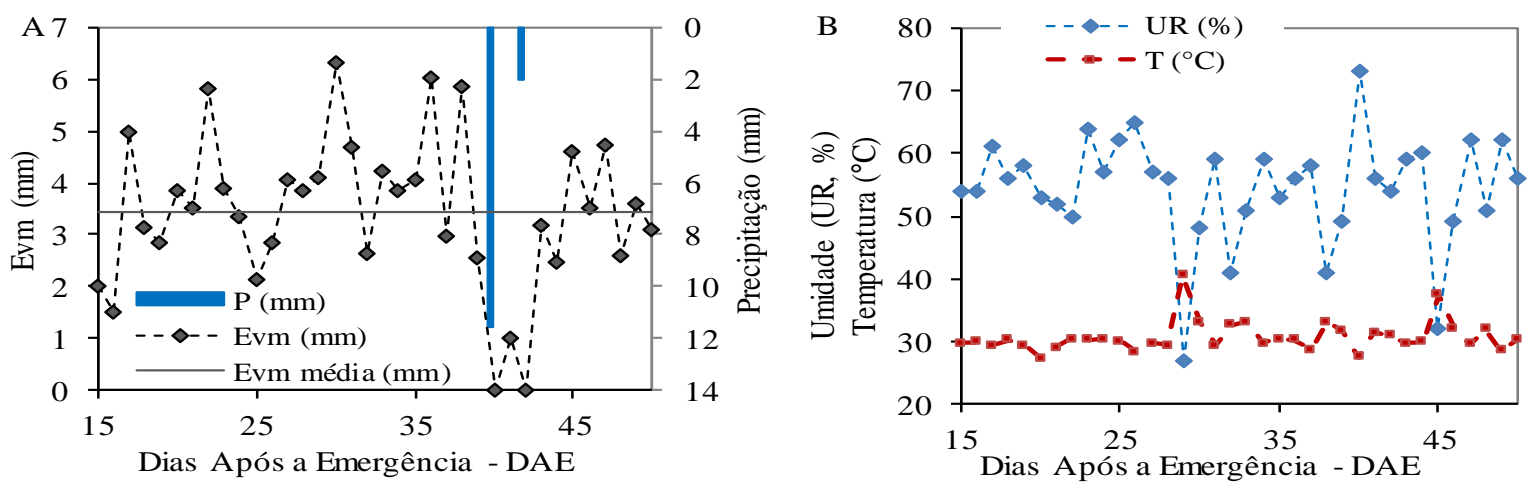

Figura 1. Evaporação e precipitação (A); temperatura do ar e umidade relativa (B), monitoradas dentro do telado agrícola.

A ANOVA apresentou interação significativa $(\mathrm{p}<0,05)$ da lâmina e frequência de irrigação para as variáveis PC e UEA (Tabela 1). Já a altura da planta (AP) foi afetada somente pela lâmina de irrigação. A média da PC foi de $1.027,6 \mathrm{~kg} \mathrm{ha}^{-1}$, com valores máximo e mínimo de 1326,6 e 552,3 $\mathrm{kg} \mathrm{ha}{ }^{-1}$ nos tratamentos L4F2 e L1F3, respectivamente. A AP média foi de $27,8 \mathrm{~cm}$, com valores máximos e mínimos de 34,0 e $17,5 \mathrm{~cm}$ para os tratamentos L4F2 e L1F3, respectivamente.

A média do UEA foi de $1,4 \mathrm{~kg} \mathrm{~m}^{-3}$, com valores máximo e mínimo de 3,1 e $0,5 \mathrm{~kg} \mathrm{~m}^{-3}$ para os tratamentos L1F1 e L5F2, respectivamente.

Tabela 1. Resumo da análise de variância e de regressão da Produtividade Comercial (PC), da Altura da Planta (AP) e do Uso Eficiente da Água (UEA) da alface americana "Gloriosa" sob cinco lâminas de irrigação e três frequências de aplicação, colhida aos 50 dias após a emergência, cultivada em telado agrícola, na área experimental do IFCE/Campus Sobral, no período de novembro a dezembro de 2013.

\begin{tabular}{|c|c|c|c|c|}
\hline \multirow{2}{*}{ Fonte de Variação } & \multirow{2}{*}{ G.L } & \multicolumn{3}{|c|}{ Quadrados médios } \\
\hline & & $\mathrm{PC}$ & AP & UEA \\
\hline Frequência & 2 & $163026,39^{* *}$ & $25,03^{\mathrm{ns}}$ & $3,66^{* * * *}$ \\
\hline Lâmina & 4 & $337775,23^{* * *}$ & $115,42^{* *}$ & $5,34^{* * * *}$ \\
\hline Frequência $v s$ Lâmina & 8 & $131101,61^{* * *}$ & $52,71^{\mathrm{ns}}$ & $0,50^{* * * *}$ \\
\hline Erro & 45 & 28106,53 & 27,63 & 0,05 \\
\hline $\mathrm{CV}(\%)$ & & 25,3 & 21,9 & 54,6 \\
\hline Média & & 1027,6 & 27,8 & 1,4 \\
\hline Modelos regressão & & \multicolumn{3}{|c|}{ Lâmina de irrigação } \\
\hline Linear & 1 & $2,06^{* * * *}$ & $141,70^{*}$ & $18,52^{* * *}$ \\
\hline Quadrática & 2 & $1,15^{* * *}$ & $192,77^{* *}$ & $10,57^{* * *}$ \\
\hline
\end{tabular}

De acordo com a análise de regressão a maior produtividade foi alcançada com as lâminas de 0,$79 ; 0,95$ e 1,25 para frequências de irrigação $F 1, F 2$ e $F 3$, respectivamente (Figura 2).

Considerando somente a lâmina de $100 \%$ da evaporação do minitanque $(124,1$ $\mathrm{mm})$, observou-se que a produção comercial (Figura 2) foi menor que as obtidas por Silva e
Queiroz (2013) e por Neves et al. (2016), os quais obtiveram produção média de $12.020 \mathrm{~kg}$ $\mathrm{ha}^{-1}$ e $22.420 \mathrm{~kg} \mathrm{ha}^{-1}$, respectivamente.

Tal fato deve-se ao ambiente de cultivo aqui estabelecido, para a alface americana, que proporcionou valores de temperatura superiores a $30,0^{\circ} \mathrm{C}$, somada à alta insolação típica de regiões equatoriais (TURINI et al., 2011). 


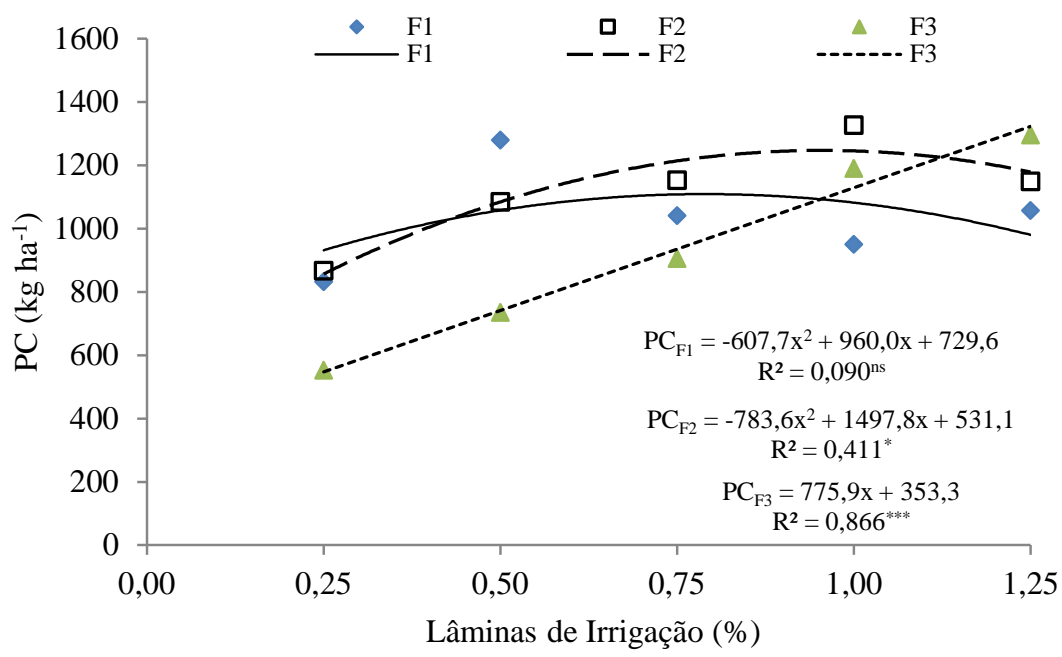

Figura 2. Produtividade Comercial - PC da alface americana "Gloriosa" em função das cinco lâminas de irrigação, colhida aos 50 DAE, cultivada em telado agrícola, na área experimental do IFCE/Campus Sobral, no período de novembro a dezembro de 2013.

A massa fresca comercial (MFC) por planta, com média de $12,7 \mathrm{~g}$ planta $^{-1}$, corrobora com os valores de PC, que também foi inferior aos valores obtidos por Marchi et al. (2015), que obtiveram em média valores próximos à $140,0 \mathrm{~g}$ planta $^{-1}$.

Neves et al. (2016) obtiveram bom resultado com a cultivar Gloriosa em condições tropicais com temperatura média de $26,0^{\circ} \mathrm{C}$, os resultados aqui apresentados indicam que esta cultivar não seja bem adaptada às condições climáticas equatoriais com temperatura diárias que superam os $30^{\circ} \mathrm{C}$.
Isso contribuiu para explicar também os resultados observados na AP (Figura 3), o qual implica-se que houve estiolamento das plantas, o que torna neste caso a temperatura como mais um fator limitante da produção, conforme preconizado por Gualberto et al. (2009).

Os resultados apresentados na Tabela 1 mostram que apenas a variável altura da planta não apresentou interação significativa $(\mathrm{p}>0,05)$ para lâmina e frequência de irrigação, contudo está foi significativa $(\mathrm{p}<0,05)$ para o fator lâmina (Figura 3).

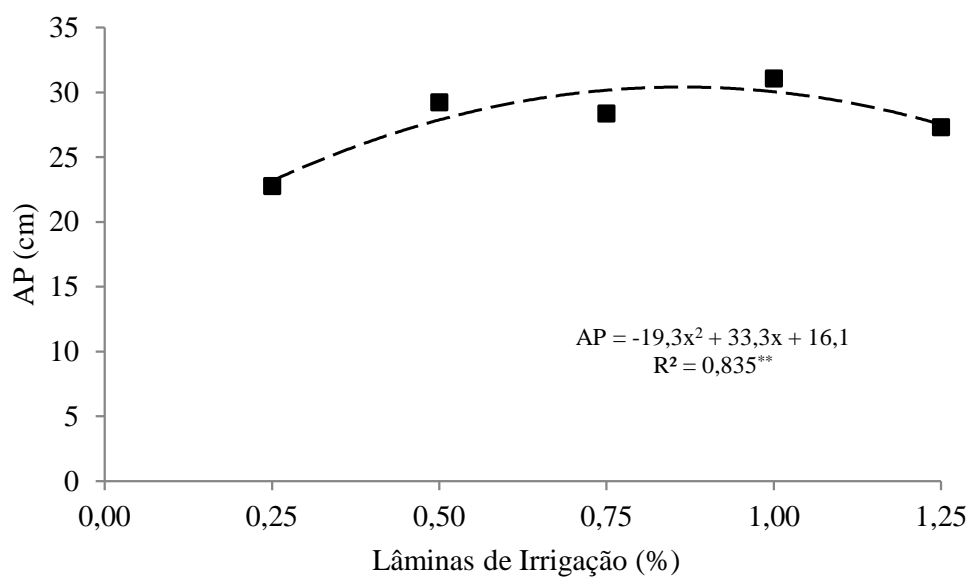

Figura 3. Altura da Planta - AP da alface americana "Gloriosa" em função das cinco lâminas de irrigação, colhida aos 50 DAE, cultivada em telado agrícola, na área experimental do IFCE/Campus Sobral, no período de novembro a dezembro de 2013. 
Os resultados da altura da planta (AP) também corroboram para explicar o efeito do clima (temperatura e radiação solar) para o estiolamento das plantas, pois os valores observados neste trabalho estão $50 \%$ acima dos observados por Silva e Queiroz (2013). Neves et al. (2016) observaram aumento na altura da planta com o aumento do sombreamento para diferentes cultivares de alface americana. Desse modo, o sombreamento do telado agrícola $(50 \%)$ pode ter contribuído para este resultado da AP.

A lâmina de 0,86 da Evm foi a que proporciona maior altura da planta conforme resultado da análise de regressão (Figura 2B). Essa lâmina é intermediaria a lâmina de maior PC observada neste trabalho, contudo, em geral AP foi superior a observada em outros trabalhos (NEVES ET AL., 2016; BRZEZINSKI et al., 2017).

Observa-se que o melhor resultado para o UEA foi obtido com as lâminas de irrigação associada a frequência $F 2$, que corresponde a aplicação de uma vez ao dia (Figura 4). Em geral, se observa que com aumento da lâmina de irrigação há uma diminuição do UEA para todas as frequências de irrigação aplicadas. Esse resultado difere do observado por Silva e Queiroz (2013), que obtiveram o maior UEA, $14,1 \mathrm{~kg} \mathrm{~m}^{-3}$, aplicando uma lâmina de $140 \%$, e o menor UEA, $9,0 \mathrm{~kg} \mathrm{~m}^{-3}$, para a lâmina de $100 \%$ da evaporação do tanque Classe A. Desse modo, torna-se importante uma avaliação econômica, principalmente quando a água for o fator limitante ao sistema de produção.

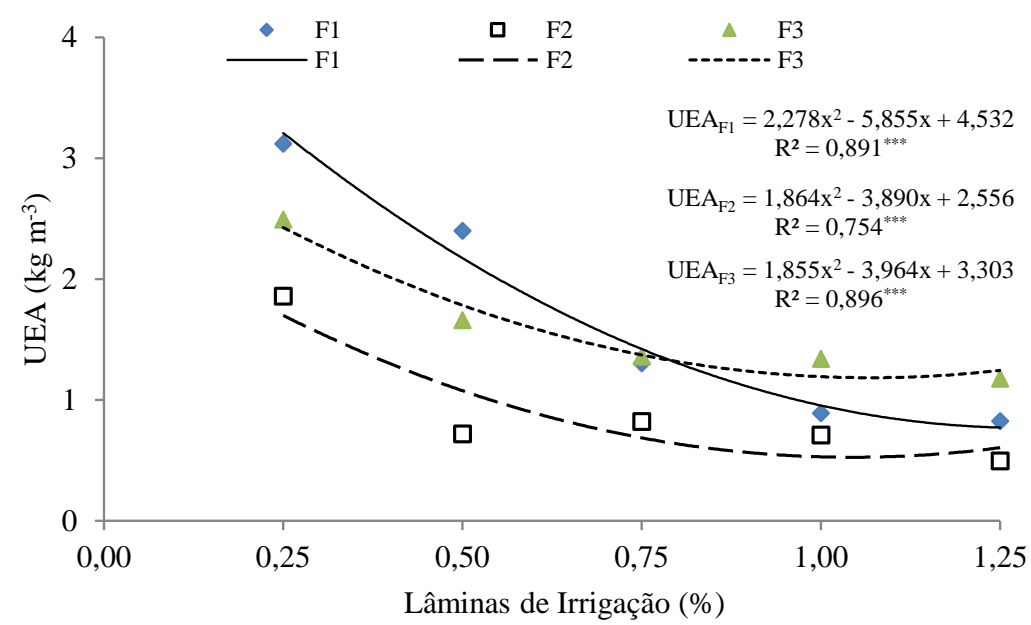

Figura 4. Uso Eficiente da Água - UEA da alface americana "Gloriosa" em função das cinco lâminas de irrigação, colhida aos 50 DAE, cultivada em telado agrícola, na área experimental do IFCE/Campus Sobral, no período de novembro a dezembro de 2013.

\section{CONCLUSÕES}

De acordo com os resultados obtidos conclui-se que as diferentes lâminas e frequências de irrigação afetaram significativamente a produção da alface americana "Gloriosa", na qual tanto o aumento da lâmina e como da frequência de irrigação promoveram aumento da produtividade da cultura.

O uso eficiente da água (UEA) foi inversamente proporcional ao aumento da lâmina de irrigação. Entre as frequências, a aplicação de água uma vez ao dia foi a que promoveu menor desempenho.

As condições climáticas observadas, principalmente as altas temperaturas, proporcionaram a não formação da cabeça da alface americana e, consequentemente, seu estiolamento.

\section{AGRADECIMENTOS}

Ao Laboratório de Ensaios em Equipamentos de Irrigação e ao Laboratório Solos do IFCE/Campus Sobral. 


\section{REFERÊNCIAS BIBLIOGRÁFICAS}

AGRIANUAL. Anuário da agricultura brasileira 2015. São Paulo: FNP Consultoria e Comércio, 2015. 187p.

AQUINO, A. B.; AQUINO, B. F.; HERNANDEZ, F. F. F.; HOLANDA, F. J. M.; FREIRE, J. M.; CRISÓSTOMO, L. A.; COSTA, R. I.; UCHÔA, S. C. P.; FERNANDES, V. L. B. Recomendações de adubação e calagem para o Estado do Ceará. Fortaleza: UFC, 1993. 248p.

BRZEZINSKI, C.R.; ABATI, J.; GELLER, A.; WERNER, F.; ZUCARELI, C. Produção de cultivares de alface americana sob dois sistemas de cultivo. Revista Ceres, v.64, n.1, p.83-89, 2017. Doi: 10.1590/0034737X201764010012

COSTA, J.N.; OLIVEIRA FILHO, P.; ALMEIDA, C.L.; SILVA, D.M.; LIMA, J.S.; VALNIR JÚNIOR, M. Reação precoce de variedades de alface à mosca minadora. Revista Agrária Acadêmica, v.2, n.5, p.7378, 2019. Doi: 10.32406/v2n52019/7378/agrariacad

GUALBERTO, R.; OLIVEIRA, P.S.; GUIMARÃES, A. Adaptabilidade e estabilidade fenotípica de cultivares de alface do grupo crespa em cultivo hidropônico. Horticultura Brasileira, v.27, p.07-11, 2009.

HENZ, G.P.; SUINAGA, F. Tipos de alface cultivados no Brasil. Brasília, Embrapa Hortaliças. 2009. 7p. (Comunicado Técnico, 75).

INMET - Instituto Nacional de Meteorologia. BDMEP - Banco de Dados Meteorológicos para Ensino e Pesquis. Estação meteorológica de Sobral, CE. Disponível em: $<$ http://www.inmet.gov.br/portal/index.php?r= bdmep/bdmep>. Acesso em: 25 nov. 2018.

KOETZ, M.; COELHO, G.; COSTA, C. C. C.; LIMA, E. P.; SOUZA, R. J. Efeito de doses de
53 potássio e da frequência de irrigação na produção da alface-americana em ambiente protegido. Engenharia Agrícola, v.26, n.3, p.730-737, 2006. Doi: 10.1590/S010069162006000300009

MARCHI, E.C.S.; MARCHI, G.; SILVA, C.A.; ALVARENGA, M.A.R. Crisphead lettuce under influence of soil conditioner, organic fertilizers and liming. Comunicata Scientiae, v.6, n.3, p.274-281, 2015. Doi: 10.14295/CS.v6i3.935

NEVES, J. F.; NODARI, I. D. E.; SEABRA JÚNIOR, S.; DIAS, L. D. E.; SILVA, L. B.; DALLACORT, R. Produção de cultivares de alface americana sob diferentes ambientes em condições tropicais. Revista Agro@mbiente On-line, v.10, n.2, p.130-136, 2016. Doi: 10.18227/1982-8470ragro.v10i2.3200

PONTE, J.P.; PONTE, E.G. Controle de doenças de plantas. Fortaleza: SEBRAE/CE, 2008. 94p.

RODRIGUES, I.N.; LOPES, M.T.G.; LOPES, R.; GAMA, A.S.; MILAGRES, C.P. Desempenho de cultivares de alface na região de Manaus. Horticultura Brasileira, v.26, p.524-527, 2008.

SALA F. C.; COSTA, C. P. da. Retrospectiva e tendência da alfacicultura brasileira. Horticultura Brasileira, v.30, n.2, 2012.

SANTOS, M. A. L.; SANTOS, D. P.; MENEZES, $\quad$ S. M.; LIMA, D. F.; VIEIRA, J. P. S. Produção da cultura da alface (Lactuca sativa $\mathrm{L}$.) em função das lâminas de irrigação Ciência Agrícola, v.13, n.1, p. 33-39, 2015.

SANTOS, S. R.; PEREIRA, G. M. Comportamento da alface tipo americana sob diferentes tensões da água no solo, em ambiente protegido. Engenharia Agrícola, v. 24, n.3, p. 569-577, 2004. 


\section{Almeida et al.}

SILVA, V.D.; QUEIROZ, S.O.P. Manejo de água para produção de alface em ambiente protegido. Irriga, v.18, n.1, p. 184-199, 2013. TURINI, T.; CAHN, M.; CANTWELL, M.; JACKSON, L.; KOIKE, S.; NATWICK, E.; SMITH, R.; SUBARRAO, K.; TAKELE, E. Iceberg lettuce production in California. California: University of California. Agricultural and Natural Resourse. 2011. 6p.
Disponível em: <http://anrcatalog.ucdavis.edu/pdf/7215.pdf $>$. Acesso em: 25 set. 2014.

VALERIANO, T.T.B.; SANTANA, M,J.; OLIVEIRA, A.F.; MACHADO, L.J.M. Alface americana cultivada em ambiente protegido submetida a doses de potássio e lâminas de irrigação. Irriga, v.21, n.3, p.620-630, 2016. 